\title{
Leaky-momentum control algorithm for voltage and frequency control of three-phase SEIG feeding isolated load
}

\author{
Duli Chand Meena*, Madhusudan Singh** and Ashutosh K. Giri*** \\ *,** Department of Electrical Engineering, Delhi Technological University, New Delhi, India \\ *** Department of Electrical Engineering, GEC, Bharuch-392002, Gujrat, India \\ *Corresponding Author : dcmeena@dce.ac.in
}

\begin{abstract}
This paper dealt the implementation of a Leaky-Momentum Control Algorithm (LMA) for controlling a voltage source converter (VSC) to enhance the power quality of a three-phase self-excited induction generator (SEIG) used in a distributed generating system. This LMA technique operates the VSC to regulate voltage and frequency of SEIG within a permissible limit. The LMA control is implemented to reduce the higher demand of reactive power, harmonics distortions and balancing of loads under different operating conditions. During the electrical and mechanical dynamical conditions, the LMA technique is maintaining a constant voltage and frequency at point of common coupling (PCC). The proposed technique is a modified control technique of basic Leaky and Momentum Algorithms. This control has removed the drawbacks of Leaky and momentum algorithms. Moreover, it is observed that LMA performs better when there are uncertainties in input conditions. The whole system comprising SEIG, nonlinear load, voltage source converter and battery storage system is made in MATLAB /SIMULINK. It has shown promising performance under both dynamical state and steady state of the system.
\end{abstract}

Keywords: Leaky - momentum algorithm; Point of common coupling; Power quality; Self-excited induction generator and total harmonic distortions.

\section{INTRODUCTION}

The problem of global warming, occurred due to exorbitant use of fossil fuels, can be reduced by distributed green and clean energy (Jha, 2011). The solar, tidal, wind, biomass, etc. can be used for generation of electricity to bring down the effect of global warming (Simoes, et al., 2008). The energy generated from the said non-conventional sources can be used for reduction of burden on the grid (Stiebler, 2008). Consequently, it is easy to regulate the frequency and voltage of a complicated power system. Due to some technological advancement in the wind technology, the electrical power generation is possible at electronic cost (Borbely, et al., 2001.). The use of SEIG has increased in wind energy generation because of its operation at different speeds. Therefore, wind energy can be generated at small scale using low cost small SEIG. The poor voltage regulation and need for reactive power support are the two major drawbacks of an induction generator. An electronic load compensator (ELC) have been developed to manage constant voltage at a fixed frequency even with variation in consumer loads (Singh, et al., 2006). Another problem with SEIG is that it draws the non-sinusoidal current from generator terminals and causes distortion of terminal voltage under nonlinear loading conditions. A modified current synchronous method with STATCOM is used for control of voltage in a SEIG-based standalone generating system (Singh, et al., 2015). A dynamic electronic load controller (DELC) is 
developed and designed to maintain constant voltage and frequency of a three-phase SEIG in paper (Chilipi, et al., 2014). It consists of VSC which provides variable reactive power under varying load conditions, and hence controls the terminal voltage. The frequency of generator is managed at constant value by dumping excess consumer load in a variable speed AC Drive connected at the DC link of converter. Two VSC of almost same rating of SEIG is required which complex and costly arrangement. Three-phase SEIG in combination with STATCOM is able to feed nonlinear loads up to its rated voltage capacity is discussed in (Singh, et al., 2006). By using DSTATCOM as a compensator, sliding mode controller along with proportional and integral controller is used for control of voltage and power quality issues of a three-phase SEIG both linear and non-linear loads conditions (Shekhar, et al., 2016). A combination of both ELC and STATCOM which is called as Decoupled Voltage and Frequency controller (DVFC) is used to control the power. Therefore, frequency the system is managed within range. The DVFC independently controls both frequency and voltage at the generator terminal is described in (Kasal, et al., 2008). An execution of DSTATCOM in a distributed power generating system with an SEIG is explained in the literature (Arya, et al., 2014). In this paper, a composite observer-based control algorithm is used for the extraction of fundamental components. A VSC controlled by implementing Lorentzian norm based adaptive filter (LAF) for power quality enhancement of SEIG in a starconnected three phase wind based distributed power generating system is described in paper (Giri, et al., 2018). LAF also neutralizes the effects of wind impulses on frequency and voltage of generator. The Least mean fourth algorithms is used for the DSTATCOM control for solving power quality issues in the grid-connected solar photovoltaic system is reported in literature (Agarwal, et al., 2017). But the acceleration problem of the convergence process is a major problem. The analysis and basics of momentum least square algorithm (MLMS) is given in the paper (Sharma, et al., 1998). The MLMS converges faster because of scaling factor. In paper (Giri, et al., 2018), Variable Learning and Gradient-based Least Mean Square (VLLMS) algorithm is implemented for control of VSC in a distributed generation. There is no effects of step size, gradient and sensor-noise on convergence performance of VLLMS algorithm due to its insensitivity to these parameters. But in LMS convergence performance is influenced by step-size parameters. A novel Leaky-least logarithmic absolute difference (LLLAD)-based control algorithm is experimentally implemented in a PV based system in paper (Kumar, et al., 2019). This technique enhanced the power quality. MLMS employs additional term called momentum Factor (Giri, et al., 2019). This factor of the control enhances the converging rate. The active and reactive power control technique for SEIG working in standalone mode is given in (Neto, et al., 2020). In nanogrid operations in standalone mode supervisory control seems good options (Kaviri, et al., 2021). However, due to slow response in randomly changing environment, its effectiveness is less. By using field programmable gate array for peak power point operation, a closed loop control technique has been developed and implemented in (Arthishri, et al., 2019). In the three phase four wire system presented in (Chauhan, et al., 2019), a generalized impedance controller is used for power control. There are few applications found which are using simple, robust, accurate and fast in dynamics adaptive control techniques but these control applications are either dependent on step size parameters or some independent gain parameters. Therefore, in this Paper, authors have decided to use the combined characteristics of leaky LMS control algorithm and momentum LMS control algorithm which is more suitable to control the system for random input type of sources such as wind energy system.

\subsection{Advantages and Novelties of Proposed Control:}

The few qualities of the anticipated control techniques are mentioned below:

1. The proposed control improves the adaptation performance instead of its current values.

2. In proposed control, the quantity of earlier gradients is used for updating the present and hence gives more precise and faster convergent results.

3. It gives the faster convergent rate and minimum probability of trapping in the local minima, in the proposed system for control of voltage and frequency in a three-phase SEIG. 
4. It provides faster dynamics in voltage and frequency control either with input or output random variations. So, authors have decided to implement an algorithm named Leaky- Momentum Control Algorithm (LMA).

\section{SYSTEM CONFIGURATION}

Figure 1, shown here, is the schematic diagram of the distributed generating system. The 3-phase SEIG is feeding power to the nonlinear load. A three-phase capacitor bank is connected in parallel at the stator terminal of the induction machine to provide the self- excitation for nominal voltage generation. The reactive power is supplied by the capacitor bank to generate nominal voltage at no load. The capacitor bank also helps to control the voltage and frequency when only linear load is connected.

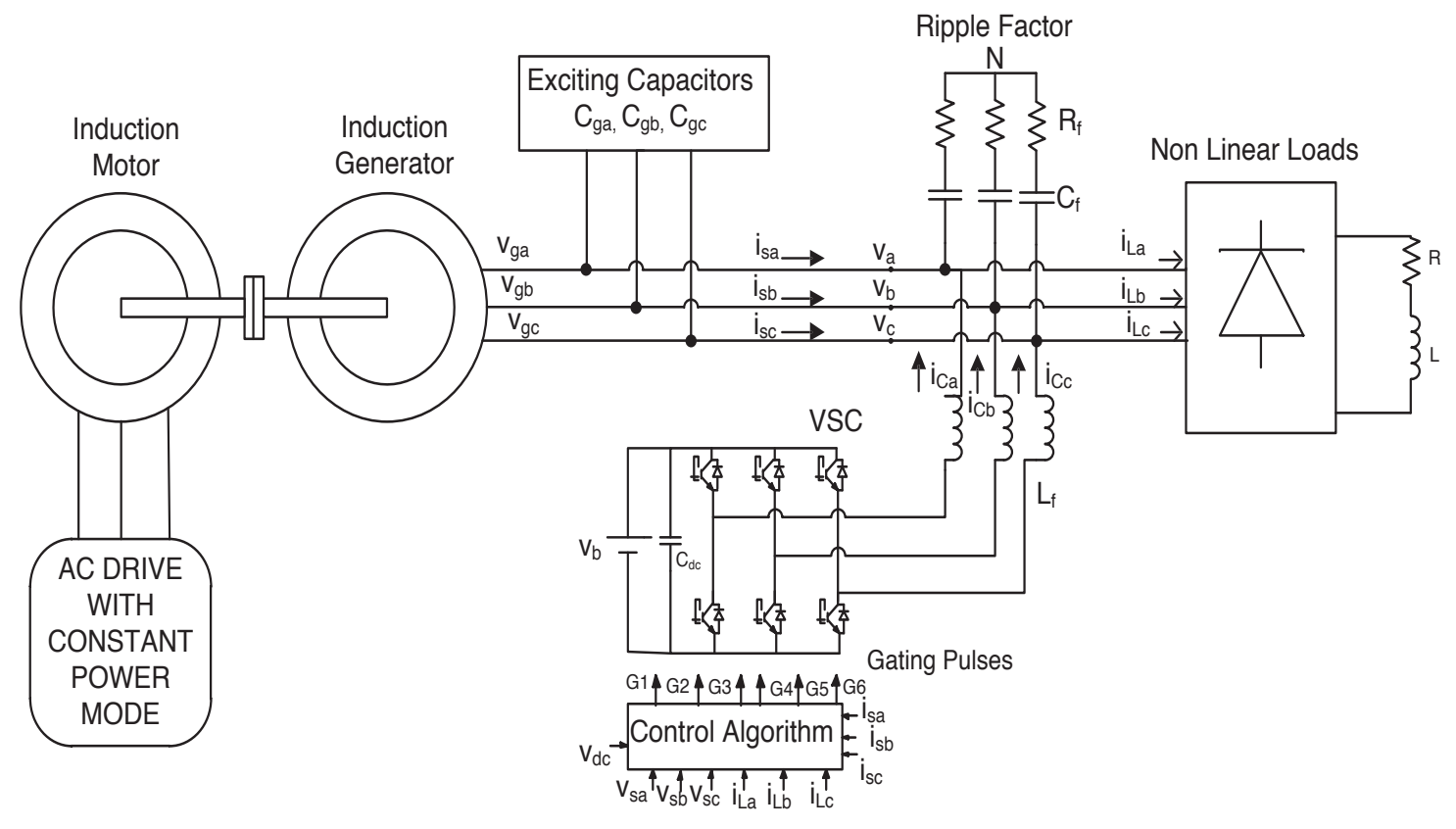

Figure 1. System Configuration

At the point of common coupling (PCC), the DSTATCOM is connected in parallel. Both reactive power and harmonics of load current are compensated by DSTATCOM. It consists three legs of insulated gate bipolar transistors (IGBTs) and three interfacing inductors and L-R elements. Three diodes with R-L Load constitutes the nonlinear load. A 3-phase star connected R-C elements connected in parallel acts as a high frequency ripple filter.

\section{LEAKY MOMENTUM CONTROL ALGORITHM}

The LMA based control algorithm used for voltage and frequency control, power balance and other power quality issues such as harmonic compensation and neutral current compensation is proposed here. The procedure for reference current estimation is elaborated below which is used to generate the switching pulses of voltage source converter.

\section{(A) Weight calculation using LMA Control Algorithm}

Terminal voltage $\left(v_{\mathrm{t}}\right)$ of SEIG is calculated using following formula: 


$$
v_{t}=\sqrt{2\left(\frac{v_{s a}^{2}+v_{s b}^{2}+v_{s c}^{2}}{3}\right)}
$$

$v_{s a}, v_{s b}$ and $\mathrm{v}_{\mathrm{sc}}$ represents instantaneous phase voltages at PCC. The in-phase unit voltage templates are calculated as follows:

$$
\begin{aligned}
& u_{p a}=\frac{v_{s a}}{v_{t}}, \quad u_{p b}=\frac{v_{s b}}{v_{t}}, \quad u_{p c}=\frac{v_{s c}}{v_{t}} \\
& {\left[\begin{array}{l}
u_{q a} \\
u_{q b} \\
u_{q c}
\end{array}\right]=\frac{1}{\sqrt{3}}\left[\begin{array}{rrr}
-1 & 0 & 1 \\
\frac{\sqrt{3}}{-\sqrt{3}} & 1 & -1 \\
2 & \frac{1}{2} & \frac{-1}{2}
\end{array}\right]\left[\begin{array}{l}
u_{p a} \\
u_{p b} \\
u_{p c}
\end{array}\right]}
\end{aligned}
$$

Where $\mathrm{u}_{p a}, u_{p b}$, and $u_{p c}$ shows unit voltages of phase $\mathrm{a}, \mathrm{b}, \mathrm{c}$ respectively. All unit voltages are instantaneous phase voltages. Similarly, $u_{q a}, u_{q b}$ and $u_{q c}$ are the quadrature phase instantaneous unit voltage templates of 3-phase voltages. A Leaky Momentum Control Algorithm is used to update the weights of active $\left(w_{p a}\right)$ and reactive $\left(w_{q a}\right)$ components of the fundamental load current. Here, the weights are adjusted till the error in the current state and previous state becomes zero. The active component of power of phase a load current is estimated as shown below:

$$
w_{p a}(n+1)=\left(1-\tau_{p} \alpha\right) w_{p a}(n)+\tau_{P} u_{p a}(n) e_{p a}(n)-u_{p a}(n) e_{n p a}(n)+\varepsilon\left(w_{p a}(n)-w_{p a}(n-1)\right)
$$

Where, $e_{\mathrm{pa}}(n)$ and $\mathrm{e}_{\mathrm{npa}}(\mathrm{n})$ are the adaptive error component and noise component of the proposed control algorithm for phase ' $a$ '.

The equations are given as follows which shows the relation between both factors:

$$
\begin{aligned}
& e_{p a}(n)=w_{s p}(n-1)-\left\{\left(1-\tau_{p} \alpha\right) w_{L p a v g}(n-1) u_{p a}(n-1)\right\} \\
& -\tau_{p}\left\{\sigma e_{p a}(n-1) i_{L a}(n-1) u_{p a}(n-1)\right\}
\end{aligned}
$$

And

$$
e_{n p a}(n-1)=k u_{p a}(n)\left\{w_{p a}(n)-w_{s p}(n)\right\}
$$

Where $w_{\text {Lpavg }}(n-1)$ is average amplitude of active power component of load current, $w_{s p}(n-1)$ is the total active components of reference supply currents and $i_{L a}(n-1)$ is load current of phase 'a' at $(\mathrm{n}-1)^{\text {th }}$ sampling instant. Other factors $k, \alpha, \sigma$ and $\tau_{p}$ are noise factor, leaky factor, error constant factor and learning rate respectively. 
Similarly, for active power components of phase b and phase c are estimated as follows:

$$
\begin{aligned}
& w_{p b}(n+1)=\left(1-\tau_{p} \alpha\right) w_{p b}(n)+\tau_{p} u_{p b}(n) e_{p b}(n)-u_{p b}(n) e_{n p b}(n)+\varepsilon\left(w_{p b}(n)-w_{p b}(n-1)\right) \\
& w_{p c}(n+1)=\left(1-\tau_{p} \alpha\right) w_{p c}(n)+\tau_{p} u_{p c}(n) e_{p c}(n)-u_{p c}(n) e_{n p c}(n)+\varepsilon\left(w_{p c}(n)-w_{p c}(n-1)\right)
\end{aligned}
$$

The average magnitude of weighted fundamental active power components is calculated by

$$
w_{L p a v g}=\frac{\left(w_{p a}+w_{p b}+w_{p c}\right)}{3}
$$

In the similar manner as estimated in above mentioned equations, reactive components of the three-phase (a, b, c) load currents can be estimated as follows:

$$
\begin{aligned}
& w_{q a}(n+1)=\left(1-\tau_{q} \alpha\right) w_{q a}(n)+\tau_{q} u_{q a}(n) e_{q a}(n)-u_{q a}(n) e_{n q a}(n)+\varepsilon\left(w_{q a}(n)-w_{q a}(n-1)\right) \\
& w_{q b}(n+1)=\left(1-\tau_{q} \alpha\right) w_{q b}(n)+\tau_{q} u_{q b}(n) e_{q b}(n)-u_{q b}(n) e_{n q b}(n)+\varepsilon\left(w_{q b}(n)-w_{q b}(n-1)\right) \\
& w_{q c}(n+1)=\left(1-\tau_{q} \alpha\right) w_{q c}(n)+\tau_{q} u_{q c}(n) e_{q c}(n)-u_{q c}(n) e_{n q c}(n)+\varepsilon\left(w_{q c}(n)-w_{q c}(n-1)\right)
\end{aligned}
$$

Where $\tau_{q}$ is the learning rate of proposed control algorithm for reactive power component estimation. The average magnitude of weighted fundamental reactive () power components is calculated by

$$
w_{L q a v g}=\frac{\left(w_{q a}+w_{q b}+w_{q c}\right)}{3}
$$

\section{Reference Source current calculation as well as Gate Pulses generation}

Reference source current is obtained by adding active and reactive components of source current obtained from the part a as below.

$$
i_{s a b c}^{*}=i_{s p t}^{*}+i_{s q t}^{*}
$$

The source current $\mathrm{i}_{\text {sabc }}$ is sensed and this estimated reference current are given at the input of hysteresis current controller for generation of gate pulses. The complete LMA control process is shown in control diagram of the system in Figure 2. 


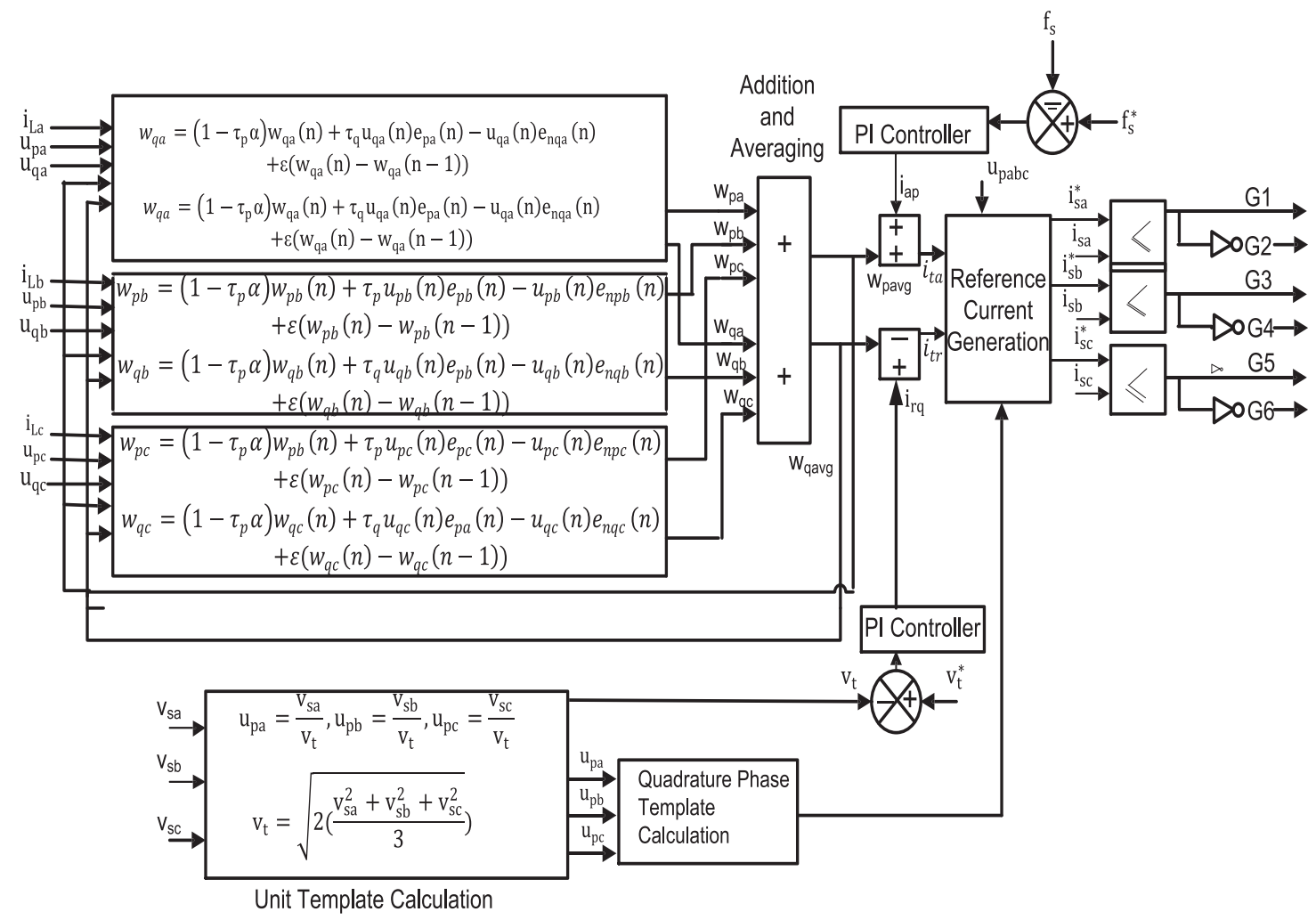

Figure 2. Block Diagram of LMA control Algorithm

\section{SIMULATION RESULTS AND PERFORMANCE ANALYSIS}

The simulation model of three-phase induction generator is developed in MATLAB with a VSC and nonlinear load. After taking into consideration various operating conditions, the simulation

study has been completed. The developed LMA control has been executed for generating control signals for VSC and regulating the voltage and frequency of proposed system. This control techniques has been used to calculate the updated weights of load current components and after finding these weights, source current reference component is computed. For mitigation of power quality problems, the designing and controlling of DSTATCOM is carried out. The simulation results are presented and explained below in these sub-sections.

\section{A. Generation of Control Signals of VSC using LMA Control Algorithm}

The LMA control technique is simulated in MATLAB/Simulink to generate control signals of the VSC for regulating three phase terminal voltages of SEIG, $\left(v_{\text {sabc }}\right)$ and frequency (f).

The magnitude of SEIG terminal voltage $\left(\mathrm{v}_{\mathrm{t}}\right)$ is determined from the sensed value of three phase voltages $\left(v_{s a}, v_{s b}, v_{\mathrm{sc}}\right)$. The active components $\left(u_{p a}, u_{p b}, u_{p c}\right)$ of unit templates are generated by dividing three phase instantaneous voltages $\left(v_{s a}, v_{s b}, v_{s c}\right)$ by magnitude of the terminal voltage $\left(\mathrm{v}_{\mathrm{t}}\right)$. Further, reactive component of unit templates $\left(u_{q a^{\prime}}, u_{q b}, u_{q c}\right)$ are derived from active components of unit templates $\left(u_{p a^{\prime}}, u_{p b^{\prime}}, u_{p c}\right)$ by using delay elements. The waveforms of phase 'a' unit templates' reactive component $\left(u_{q a}\right)$ and active component $\left(u_{p a}\right)$ of source current have been shown in Fig.3, which are in quadrature with each other. The MLA control is being used to update the 
fundamental active and reactive component $\left(u_{p q}, u_{p b}, u_{p c}\right)$ and $\left(u_{q a^{\prime}}, u_{q b}, u_{q c}\right)$ of the load current $\left(i_{a b c L}\right)$ are presented in Figure 3. The LMA updates these active and reactive components of three-phase templates $\left(\mathrm{w}_{\mathrm{pa}}, \mathrm{w}_{\mathrm{pb}}, \mathrm{w}_{\mathrm{pc}}\right)$ and $\left(\mathrm{w}_{\mathrm{qa}}, \mathrm{w}_{\mathrm{qb}}, \mathrm{w}_{\mathrm{qc}}\right)$ respectively till the error in unit templates and load currents are converged.

After determining the error between load current and unit templates of active and reactive currents separately, the leaky and momentum term of the weights i.e., $\mathrm{W}_{\mathrm{L}}$ and $\mathrm{W}_{\mathrm{m}}$ are calculated and active and reactive components of error templates are updated accordingly.

Under varying load conditions, the variation of these weights (WL, Wm) are shown in Fig.3. It is observed that leaky weight factor $\left(\mathrm{W}_{\mathrm{L}}\right)$ is varied as the load current $\left(i_{a b c L}\right)$ changes.

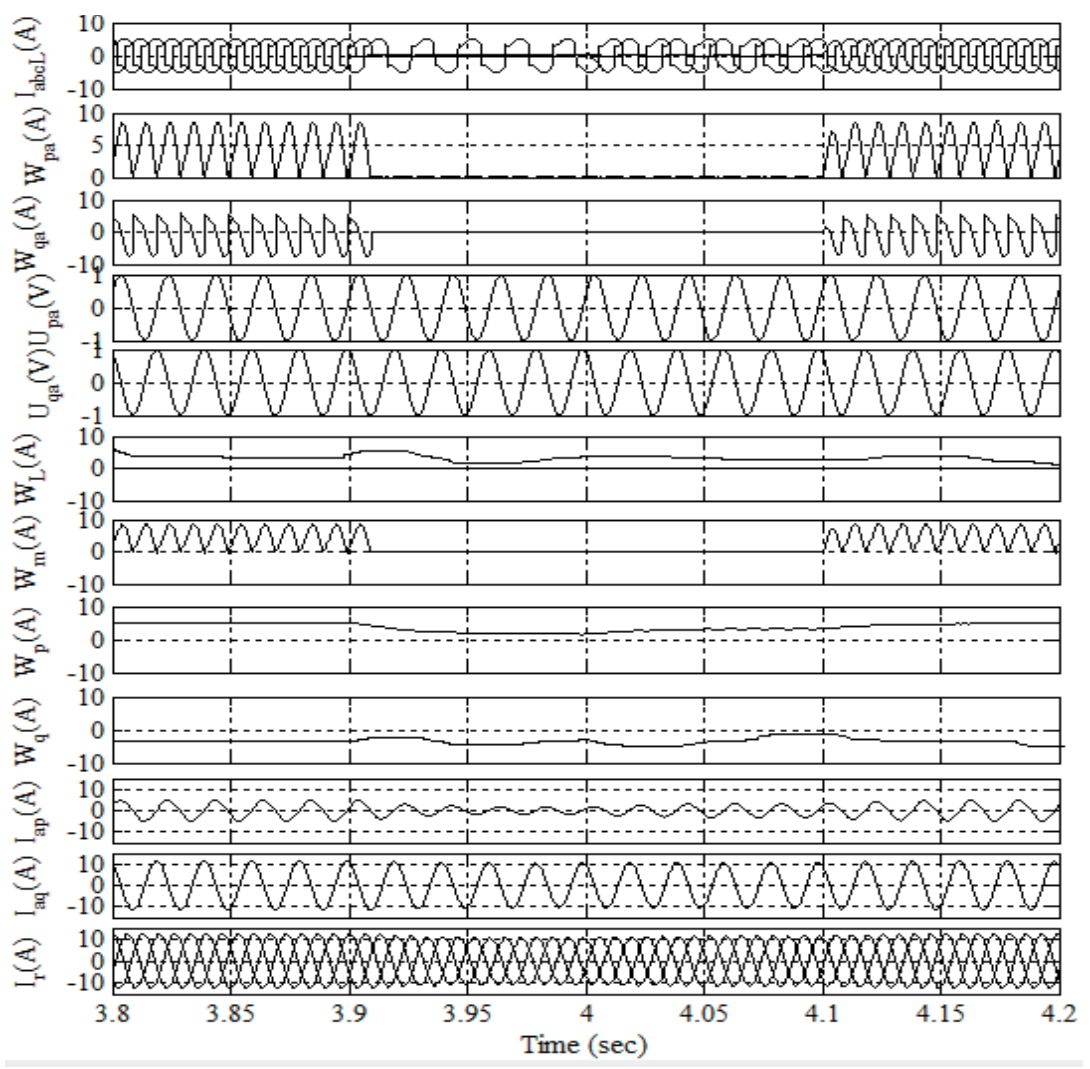

Figure 3. Simulation Results of Reference Current Generation Process

The average active weight of all three phase $(\mathrm{Wp})$ and average reactive component weight factor (Wq) are determined to obtain the magnitude of active power component of load current. The variation of these weights is also shown in Figure 3. Total magnitude of reference active real power component of load current is calculated through sum of average active weight (WL) and frequency, proportional integral output. The summation block output is multiplied with active unit templates of the reference load current and generated reference current corresponding to fundamental load current component (ILp). Similarly, the output of PI controller is deducted from the average weight of reactive currents for regulating the terminal voltage to determine magnitude for component of reactive power of the load $\left(\mathrm{I}_{\mathrm{aq}}\right)$. These active and reactive reference currents are shown in Fig.3. 
B. LMA Control Algorithm Performance for Voltage and Frequency Control under Load Variation
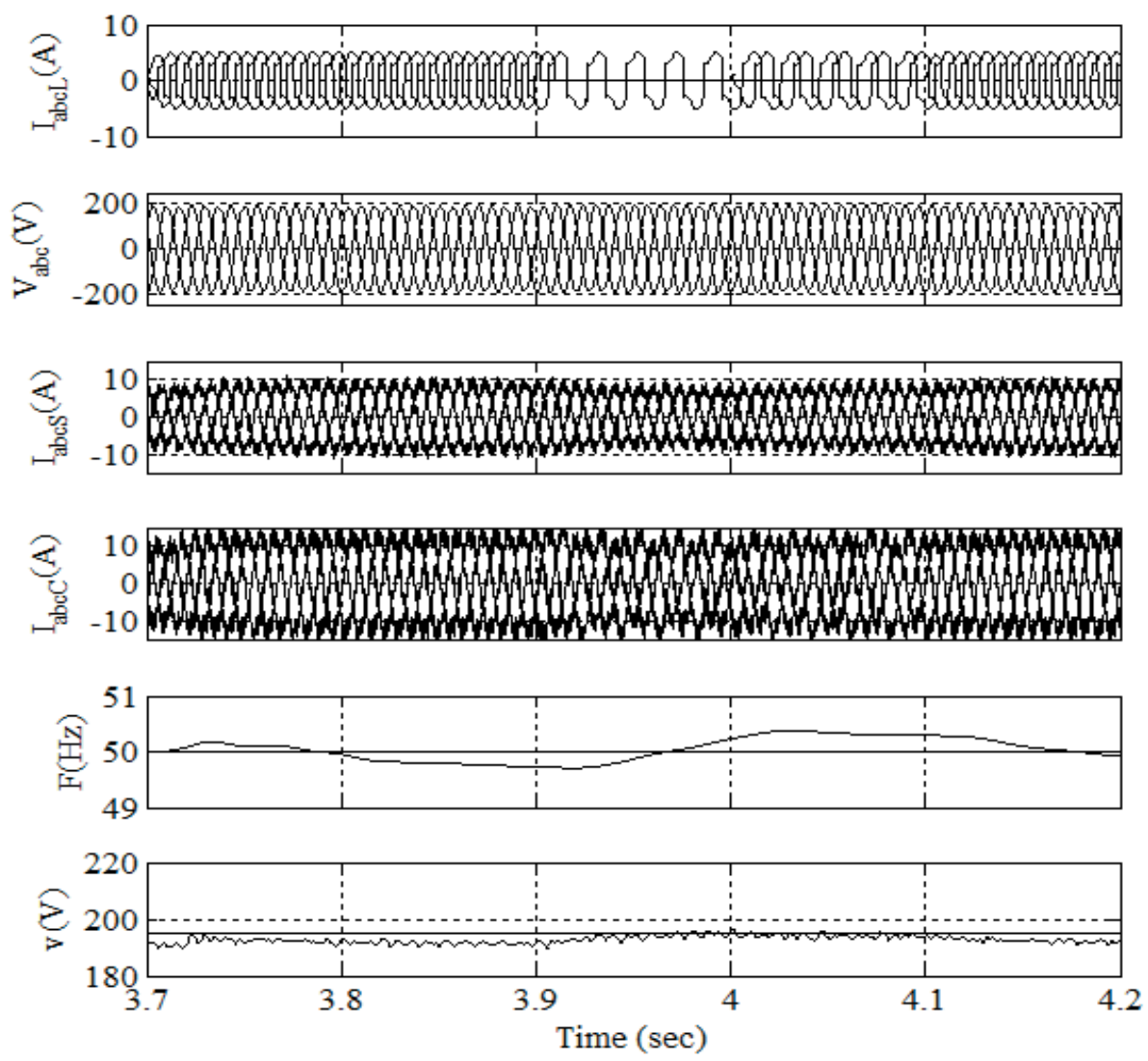

Figure 4. Simulation Performance of LMA Control Algorithm for voltage and Frequency Control under Load Variation.

Fig. 4 shows the variation of the SEIG terminal voltages (Vabc), currents (IabcS), nonlinear load currents (IabcL), VSC currents (IabcC), frequency (F) and dc-link voltage , V while worst case switching in load from 3-phase to 1-phase and subsequently 2-phase conditions. It is observed that SEIG is started with initial 3-phase load with terminal phase voltages about $130 \mathrm{~V}(\mathrm{rms})$. At $\mathrm{t}=3.9 \mathrm{sec}$. the load currents in phase ' $\mathrm{b}$ ' and ' $\mathrm{c}$ ' are suddenly interrupted causing severe unbalance in load current i.e. $\mathrm{ib}=\mathrm{ic}=0$, ia $=\mathrm{iaL}$. However, due to the presence of VSC, the SEIG terminal currents are still balance, and as VSC supplement the necessary current and therefore the compensating currents (iabcC) of VSC are also unbalanced till unbalance in the load sustain till $\mathrm{t}=4.1 \mathrm{sec}$. Further, it is clear that the SEIG phase voltage (Vabc) remain balanced despite the unbalances in the load. Also, the frequency $(\mathrm{F})$ of the system remain in close proximity of $50 \mathrm{~Hz}$, since the battery energy storage system at DC link ensure balance between power generated and power consumed during variations of load. 


\section{Power Balance During Sudden Change in Load}
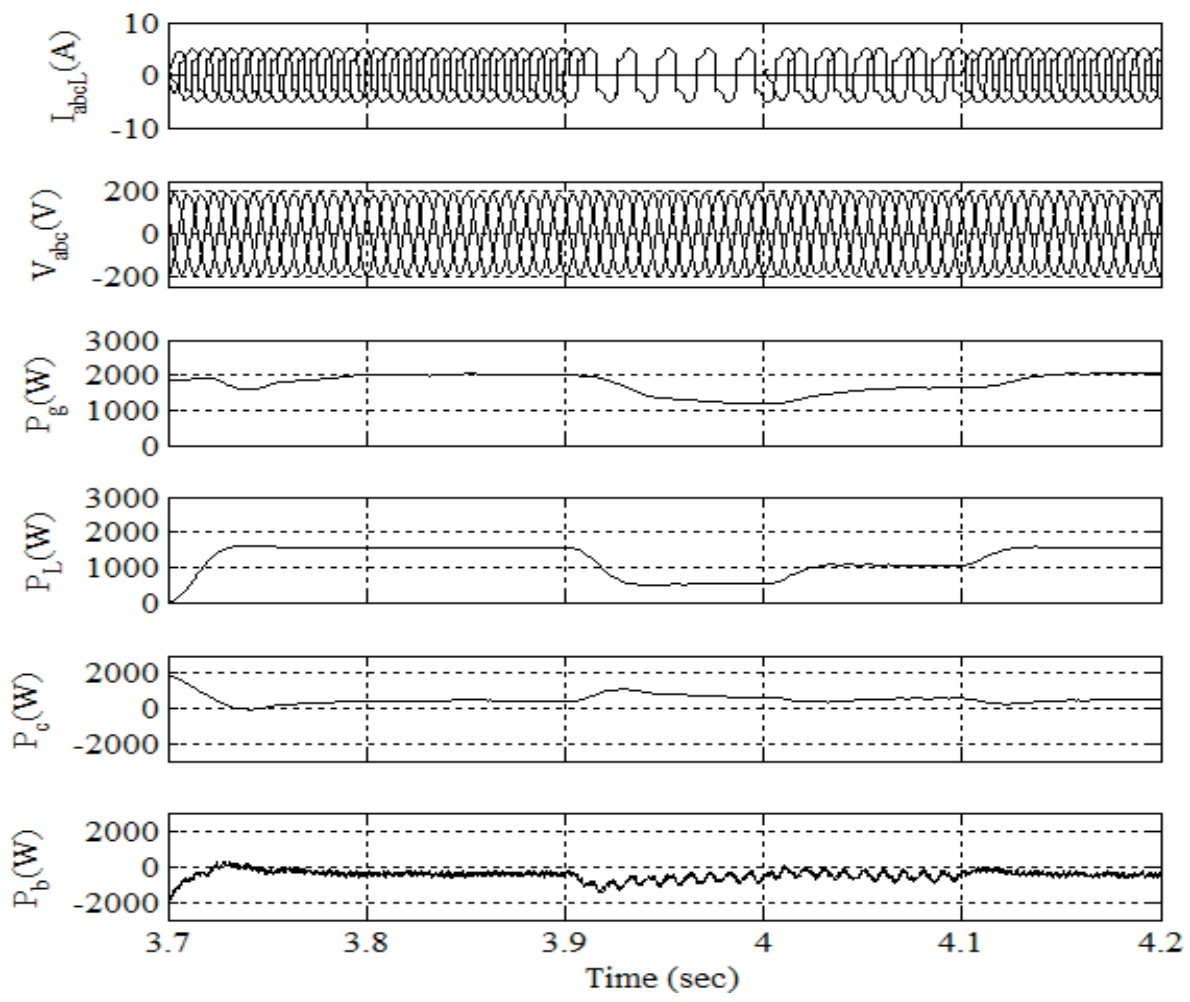

Figure 5. Simulation performance of LMA during power dynamics of system.

Fig. 5 shows the variation of load currents (IabcL), SEIG terminal voltage (Vabc), the generated real power (Pg), real power consumed in the load (PL) and real power support from VSC (Pc) and power in BESS (Pb). It is observed that during $\mathrm{t}$ is equal to $(0-3.9)$ second, when load is constant, SEIG generates $2 \mathrm{~kW}$ out of which about $1.5 \mathrm{~kW}$ is consumed in fixed nonlinear load and balance $500 \mathrm{~W}$ is being utilized in charging of BESS at DC link of VSC. When loads of phases 'b', and 'c' are suddenly opened at $t$ is equal to $3.9 \mathrm{sec}$. and load power is reduced to a about $500 \mathrm{~W}$, the VSC absorb more real power in BESS and the difference between generated power $(\mathrm{Pg})$ and power consumed $(\mathrm{PL}+\mathrm{Pc})$ are maintained and therefore frequency $(\mathrm{F})$ of the system is maintained close to $50 \mathrm{~Hz}$ even in isolated mode of operation of SEIG.

\section{Power Quality Indices in Steady State Condition}

Fig. 6(a), 6(b) and 6(c) shows THD in SEIG terminal voltage (va), SEIG phase 'a' current (ia ) and load current ( iL ) under steady state conditions. THD observed in terminal voltage is only $1.9 \%$. Further, the load being nonlinear has very high THD it's about $31.31 \%$, but still the SEIG current THD is about $4.02 \%$. It is clear that LMA is not only effective in regulating voltage and frequency of SEIG based isolated energy generation systems but equally well in elimination of harmonics from source currents. 

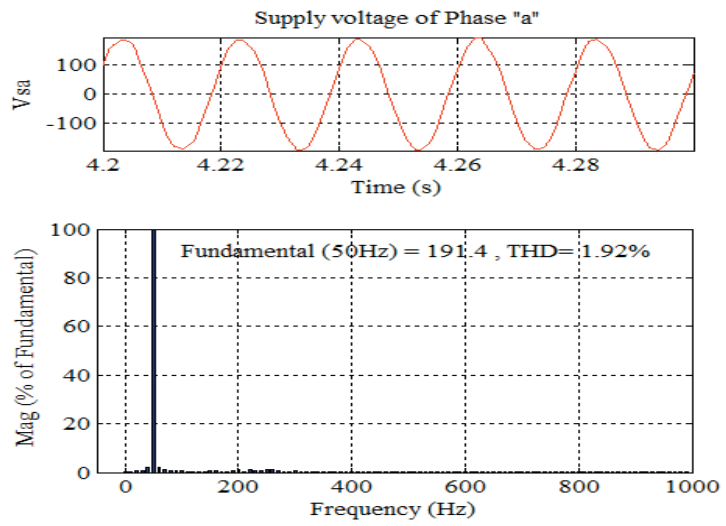

(a)
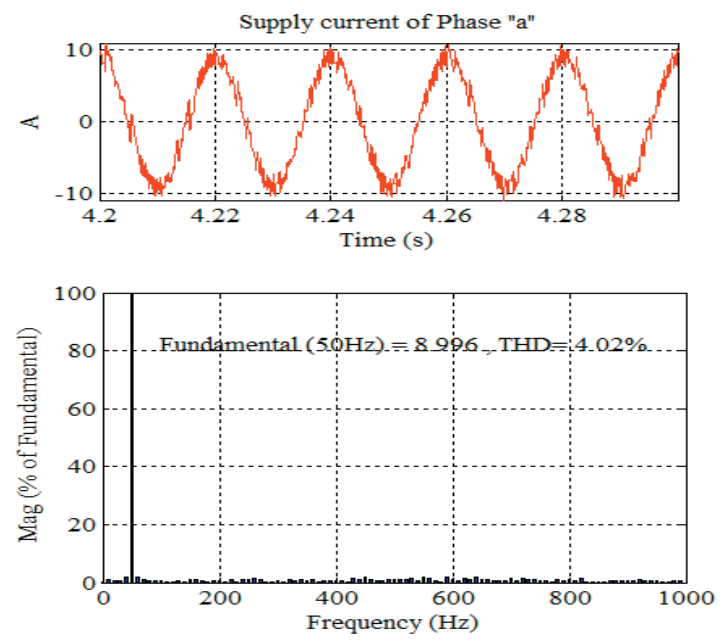

(b)
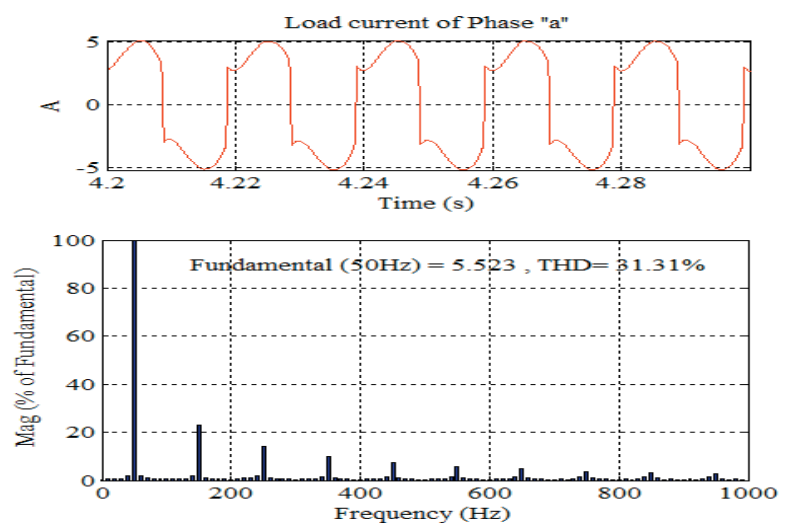

(c)

Figure 6 Simulation Results of Harmonic distortion steady state (a) THD in phase 'a' of supply voltage (b) THD in phase 'a' of supply current (c) THD in Load current of phase ' $a$ '. 


\section{CONCLUSION}

A three-phase SEIG based distributed generating system with improved power quality issues have been studied. The main objective of this paper was to discuss the effectiveness of leaky momentum control algorithm in wind based distributed energy system which is always exposed to random input variations. The LMA is used for regulation of voltage and frequency of the system. It has also solved the problems of harmonic mitigation, reactive power compensation and load unbalancing. Due to effectiveness of the proposed control, despite high value of harmonics in the load current (31.1\%), the source voltage and current harmonics are less than 5\% and that is acceptable as per IEEE standards-519. This algorithm is very effective in a suddenly changing environment. In dynamic conditions it is observed that the dc link voltage has been controlled within the limits. The predicted scheme is having notable higher convergence rate.

\section{REFERENCES}

Jha, A.R. 2011. The Wind Turbine Technology. CRC Press. London, U.K.

Simoes, M. Godoy \& Farret, F.A. 2008. Alternate Energy Systems, Design and Analysis with Induction Generators. 2nd ed. CRC Press. London, U.K.

Stiebler, M. 2008. Wind Energy Systems for Electric Power Generation, Green Energy-I and Technology. SpringerVerlag. Berlin, Germany.

Borbely, A.M. \& Keider, Jan F. 2001. Distributed Generation: The Power Paradigm for the New Millenium. CRC Press. Boca Raton, FL, USA.

Singh, B., Murthy, S. S. \& Gupta, S. 2006. Analysis and Design of Electronic Load Controller for Self-Excited Induction Generators. IEEE Transactions on Energy Conversions. 21(1): 285-93.

Singh, B., Murthy, S. S., Reddy, R. S. \& Arora, P. 2015. Implementation of modified current synchronous detection method for voltage control of self-excited induction generator. IET Power Electronics. 8(7): 1146-55.

Chilipi, R. R., Singh, B., Murthy, S. S. \& Madishetti, S. 2014. Design and implementation of dynamic electronic load controller for three-phase self-excited induction generator in remote small-hydro power generation. IET Generation, Transmission \& Distribution. 8(9): 1528-38.

Singh, B., Murthy, S. S. \& Gupta, S. 2006. STATCOM-Based Voltage Regulator for Self- Excited Induction Generator Feeding Nonlinear Loads. IEEE Trans. on Ind. Electro. 53(5): 1437-52.

Shekhar, V. C., Kant, K. \& Singh, B. 2016. DSTATCOM supported induction generator for improving power quality. IET Renewable Power Generation. 10(4): 495-503.

Kasal, G. K. \& Singh, B. 2008. Decoupled voltage and frequency controller for isolated asynchronous generators feeding three-phase four-wire loads. IEEE Transactions on Power Delivery. 23(2): 966-73.

Arya, S. R., Singh, B., Niwas, Ram, Chandra, A. \& Al-Haddad, K. 2014. Power-Quality Enhancement using DTATCOM in Distributed Power Generation System. IEEE International Conference on Power Electronics, Drives and Energy Systems (PEDES). Mumbai, India.

Giri, A. K., Arya, S. R., Maurya, R. \& Babu, B. C. 2018. Power Quality Improvement in Stand- alone SEIGBased Distributed Generation System Using Lorentzian Norm Adaptive Filter. IEEE Transactions on Industry Applications. 54(2): 5256-66.

Agarwal, R.K., Hussain, I. \& Singh, B. 2017. Implementation of LLMF control algorithm for Three-phase grid-tied SPV-DTATCOM system. IEEE Transactions on Industrial Electronics. 64(9): 7414-24. 
Sharma, R., Sethares, W. A. \& Bucklew, J. A. 1998. Analyis of Momentum Adaptive Filtering Algorithms. IEEE Trans. Signal Process. 46(5): 1430-34.

Giri, A. K., Arya, S. R., Maurya, R. \& Mehar, R. 2018. Variable learning adaptive gradient based control algorithm for voltage source converter in distributed generation. IET Renewable Power Generation. 12(16): 1883-92.

Kumar, Nishant, Singh, B., Panigrahi, B. K. \& Xu, Lie. 2019. Leaky- Least- logarithmic Absolute -Differencebased control algorithm and learning-based InC MPPT Technique for Grid-Integrated PV System. IEEE Transactions on Industrial Electronics. 66(11): 9003-12.

Giri, A. K., Arya, S. R. \& Maurya, R. 2019. Compensation of Power Quality Problems in Wind-Based Renewable Energy System for Small Consumer as Isolated Loads. IEEE Transactions on Industrial Electronics. 66(11): $9023-31$

Neto, Pedro José dos Santos, Pinto, Adeon Cecílio, André, dos Santos Barros Tárcio \& Filho, Ernesto Ruppert. 2020. A Proposal to Control Active and Reactive Power in Distributed Generation Systems Using Small Wind Turbines. IEEE Latin America Transactions. 18(10): 1699-706.

Kaviri, Sajjad Makhdoomi, Hajebramini, Hadis, Poorali, Behzad, Pahlevani, Majid, Jain, Praveen K., \& Bakhshai, Alireza. 2021. A Supervisory Control System for Nanogrids Operating in the Stand-Alone Mode. IEEE Transactions on Power Electronics. 36(3):2914-31.

Arthishri, K., Kumaresan, N. \& Gounden, N. Ammasai. 2019. Analysis and Application of Three-Phase SEIG with Power Converters for Supplying Single-Phase Grid from Wind Energy. IEEE Systems Journal. 13(2): 1813 -22.

Chauhan, P. J. \& Chatterjee, J.K. 2019. A Novel Speed Adaptive Stator Current Compensator for Voltage and Frequency Control of Standalone SEIG Feeding Three-Phase Four-Wire System. IEEE Transactions on Sustainable Energy.10(1): 248 - 56.

\section{APPENDIX}

3-PHASE SEIG Ratings and various Parameters.

(A) Ratings: 5hp, 4-pole, $50 \mathrm{Hertz}, 230 \mathrm{~V}$, and 4-pole, $R_{s}=2.93 \Omega$, mutual inductance $=26.7544 \mathrm{mH}$, rotor resistance $R_{r}=0.4816 \Omega$, rotor inductance $L_{r}=2.016 \mathrm{mH}$, Inertia constant $(\mathrm{H})=J\left(\mathrm{Kg} \mathrm{m}^{2}\right)$, Friction constant $=$, Excitation capacitor $=4.5 \mathrm{kVAR}$.

(B) Compensator parameters: $L_{s}=4 \mathrm{mH} ; R_{f}=8 \Omega ; C_{f}=12 \mu \mathrm{F} ; C_{d c}=3000 \mu \mathrm{F}$.

(C) Nonlinear load: diode bridge with $\mathrm{R}=30 \Omega, \mathrm{L}=100 \mathrm{mH}$ in each phase. 